\title{
MODERN ASPECTS OF CLINICO-PATHOLOGICAL CHARACTERISTICS AND TREATMENT OF MALIGNANT COLONIC OBSTRUCTION
}

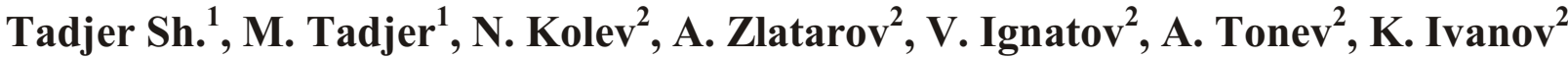 \\ ${ }^{1}$ National Multiprofile Transport Hospital "Tsar Boris III" - Sofia \\ ${ }^{2}$ UMHAT "St. Marina" - Varna, First Clinic of Surgery
}

Reviewed by: assoc. prof. P. Ghenev

\begin{abstract}
The colorectal cancer is diagnosed at its complicated stage in 40 to $60 \%$, including $35 \%$ with symtptoms of colonic obstruction The postoperative mortality remains high, as well as the lethality. Our aim is to study the up-to-date aspects in the clinico-pathological characteristics and treatment of malignant colonic obstruction (colon ileus-cancer). From 1009 patients operated for 24 years (1982-2005) with colorectal cancer with median age 67 years 378 patients $(37.4 \%)$ were over 70 years. The most important aim is to overcome the obstruction and restore the intestinal passage and if possible perform a resection of the tumor. The surgical tactics in case of malignat obstruction of the right colon is well described in the literature, but the question of tactics in case of left colon remains - single or double-stage operation. Other methods have also been discussed, such as cecostomy, NdYAG laser vaporization of the obstructing tumor. The stenting is related with significant advantages and is used for palliative procedures or as a bridge to surgery.
\end{abstract}

Key words: colorectal cancer, emergency surgery, colonic obstruction

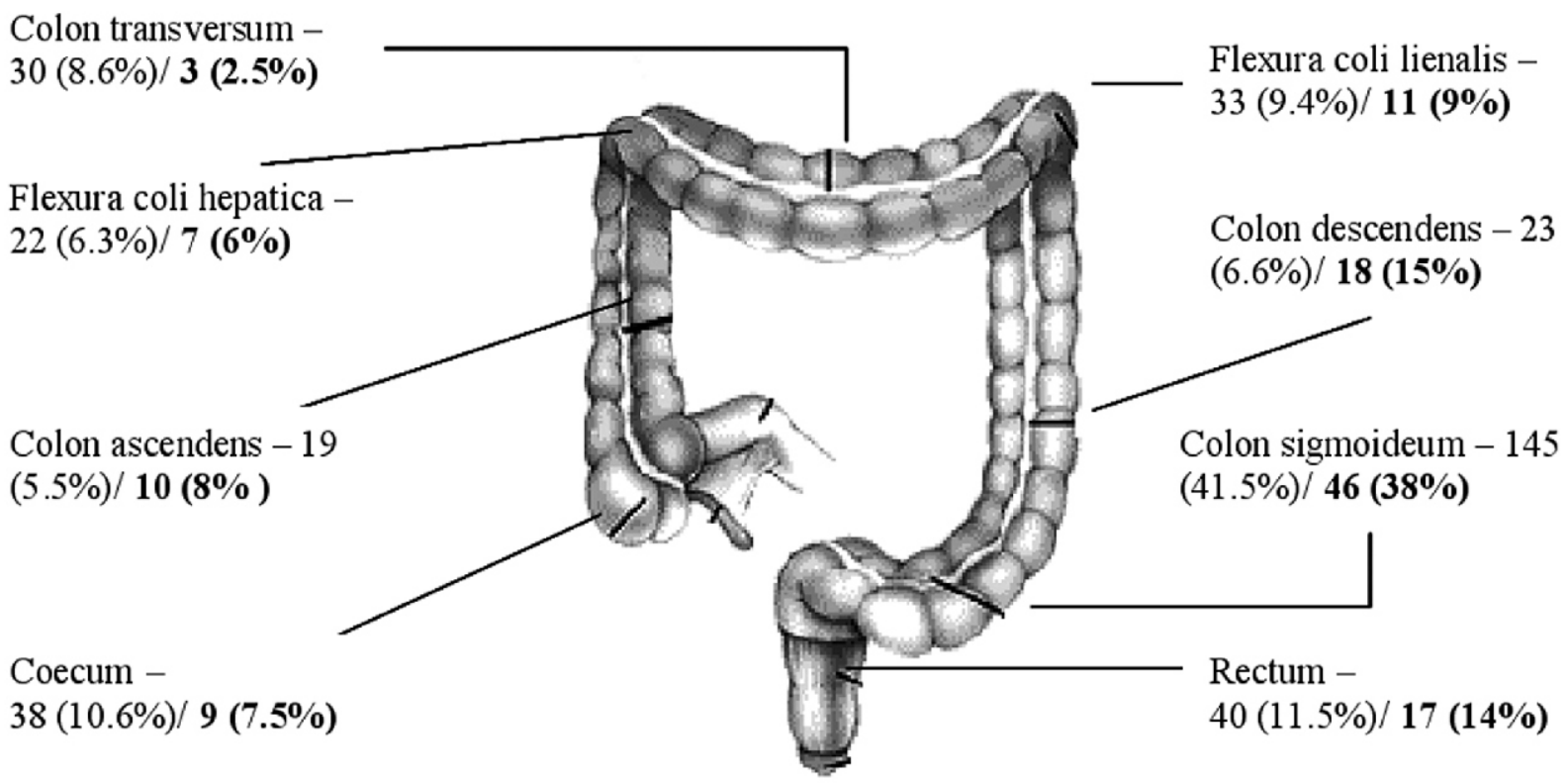

Fig. 1. Localization of malignant obstruction

Address for correspondence:

A. Zlatarov, UMHAT "St. Marina" - Varna, First Clinic of Surger Varna, Bulgaria, 1 Hristo Smirnenski blvd, $6^{\text {th }}$ floor,

e-mail: alekszlatarov@gmail.com
The most frequent cancer in the American population is the colorectal cancer and is the second leading cause for lethality. In the USA 135000 to 160000 new cases are found yearly and 60000 are the deceased patients. The incidence in Europe is increasing (25/100 000), as for the Scan- 


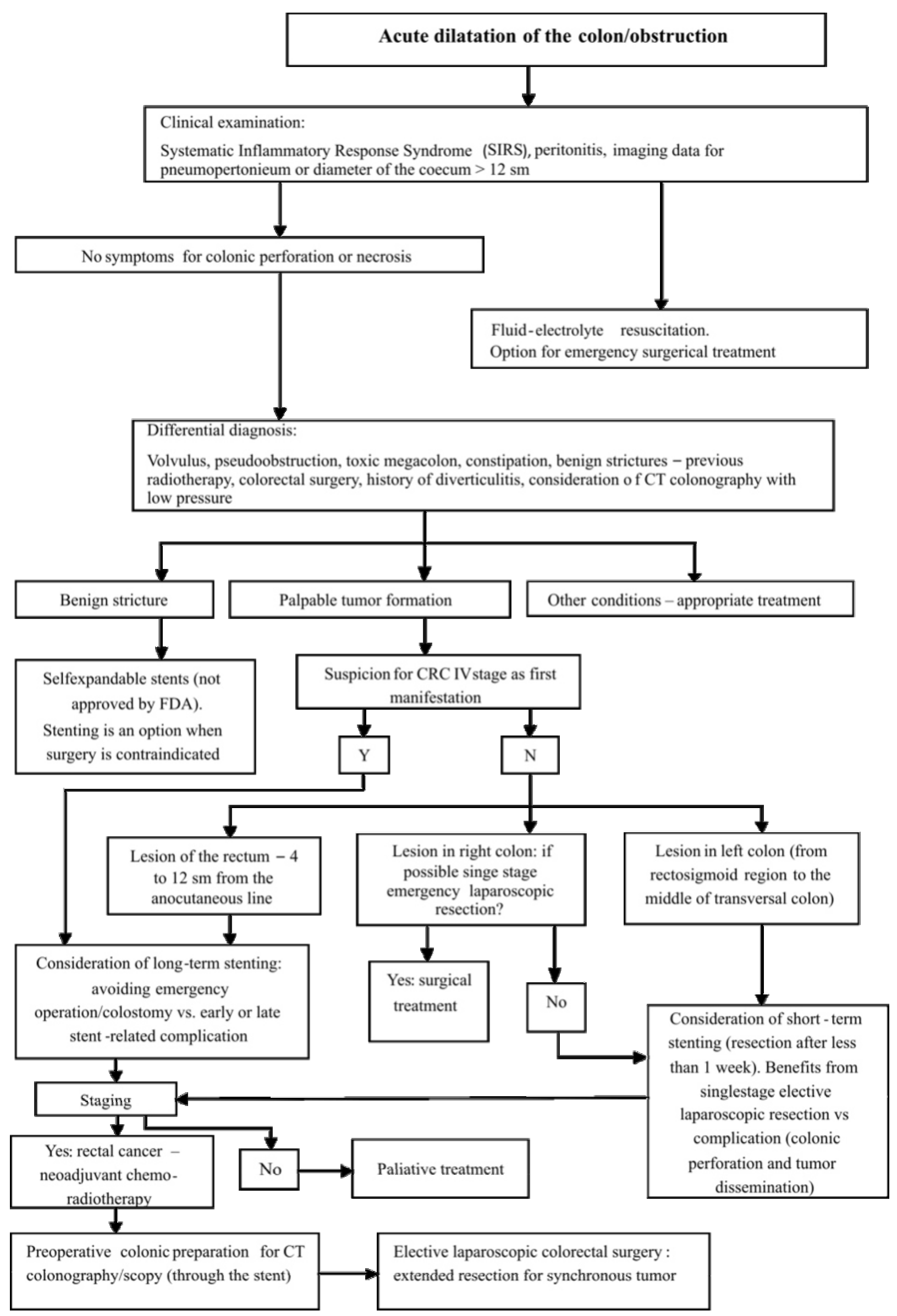

Fig. 2. Algorithm for treatment of acute malignant colo-rectal obstruction (Bonin E., Todd H. Baron, 2010, (4). 
dinavian countries it reaches 35/100 000. In Austria 5000 new cases are found yearly, and in the world - 572000 (23). The colon cancer takes the third most common oncological disease in the USA - 106100 develop the disease yearly and 49920 have deceased in 2009 (4).

The colonic obstruction in the USA is a common reason for hospitalization - $15 \%$ emergency admittance with abdominal pain or 300000 hospitalizations yearly; the increase is $3 \%$ for patients with cancer and for patients with colorectal cancer tumour is $10-28 \%$.

In 2006 in Europe 412900 new cases of colon cancer have been registered and 207400 have deceased (12).

The colorectal cancer is diagnosed at its complicated stage in 40 to $60 \%$, including $35 \%$ with symtptoms of colonic obstruction $(9,19)$. For elderly patients the complicated stages vary from $42.5 \%$ to $86.2 \%$ (2). The postoperative mortality remains high about $30 \%(2,7,13,16)$. Despite the significantly better results $(2,9,19,23)$ in unselected group of patients, the lethality remains daunting high - above $20 \%$ $(2,9,19)$.

Our aim is to study the up-to-date aspects in the clinico-pathological characteristics and treatment of malignant colonic obstruction (colon ileus-cancer).

The surgical tactics is based on the following factors: localization of the cancer, duration of the operation, the operations being primary discontinuity resections, anus praeternaturalis, primary resections with anastomosis, by-pass anastomoses.

The surgical strategy in treatment of malignant obstruction of the colon cancer includes:

- colostomy, ileostomy;

- coecostomy;

- three-stage resections;

- Hartmann's resection (two-stage resection)

- Subtotal colectomy;

- Segment resection with intraoperative lavage;

- Segment resection without decompression or by-pass operation;

- NdYAG photoablation;

Tabl. 1. Localization of the colorectal cancer in elective and emergency operations (Pavlidis T.E. et al.)

\begin{tabular}{||l|c|c||}
\hline \hline Localization & Elective surgery & Emergency surgery \\
\hline Cecum & $92(10.5 \%)$ & $9(7.5 \%)$ \\
\hline Ascending colon & $65(7.3 \%)$ & $10(8 \%)$ \\
\hline Hepatic flexure & $38(4.3 \%)$ & $7(6 \%)$ \\
\hline Transversal colon & $52(6 \%)$ & $3(2.5 \%)$ \\
\hline Splenic flexure & $18(2 \%)$ & $11(9 \%)$ \\
\hline Descending colon & $29(3.2 \%)$ & $18(15 \%)$ \\
\hline Sigma & $259(29 \%)$ & $46(36 \%)$ \\
\hline Rectum & $335(37.7 \%)$ & $17(14 \%)$ \\
\hline TOTAL & $\mathbf{8 8 8}$ & $\mathbf{1 2 1}$ \\
\hline \hline
\end{tabular}

- Endoluminal stenting.

The obstructive cancer is most commonly located in the sigma and rectum (53\%), cecum (10.6\%), ascending (5.5\%) and descending colon (6.6\%). The proportion of left and right colon (in our study over 350 patients with malignant obstruction, who underwent surgery) is $241(68.6 \%)$

Tabl. 2. Progression of the colorectal cancer in elective and emergency surgery (no Pavlidis T.E. et al.)

\begin{tabular}{||l|c|c||}
\hline \hline Progression & Elective surgery & Emergency surgery \\
\hline No progression & $638(72 \%)$ & $50(57.8)$ \\
\hline $\begin{array}{l}\text { Invasion of adjacent } \\
\text { organ }\end{array}$ & $107(12 \%)$ & $17(14 \%)$ \\
\hline Liver metastases & $116(13 \%)$ & $22(18.2 \%)$ \\
\hline $\begin{array}{l}\text { Desseminated } \\
\text { peritoneal carcinosis }\end{array}$ & $27(3 \%)$ & $12(10 \%)$ \\
\hline Total & $\mathbf{8 8 8}$ & $\mathbf{1 2 1}$ \\
\hline \hline
\end{tabular}

vs. $79(22.6 \%)$ - three times less frequently than in the left colon. This data is correlating to those found in the literature - 75 (62\%) v.s. 29 (24\%) (Pavlidis T.E. et al.)

The surgical tactics in case of malignat obstruction of the right colon is well described in the literature, but the question of tactics in case of left colon remains - single or double-stage operation $(2,9,19,21)$.

The complete obturation is an emergency condition, which requires urgent decompression because of dilation of the colon, bacterial dislocation, fluid and electrolyte imbalance, risk of necrosis and perforation of the colon.

Tabl. 3. Performed planned and emergency operations for colorectal cancer (Pavlidis T.E. et al.)

\begin{tabular}{||l|c|c||}
\hline Planned & $\begin{array}{c}\text { Emergency } \\
\text { surgery }\end{array}$ \\
\hline Colostomy & $25(2.7 \%)$ & $23(19 \%)$ \\
\hline Right hemicolectomy & $188(21.5 \%)$ & $22(18 \%)$ \\
\hline $\begin{array}{l}\text { Resection of colon } \\
\text { transversum }\end{array}$ & $24(2.7 \%)$ & - \\
\hline $\begin{array}{l}\text { Left hemicolectomy } \\
\text { Resection of sigma with } \\
\text { anastomosis }\end{array}$ & $46(5 \%)$ & $12(10 \%)$ \\
\hline \begin{tabular}{l} 
Hartmann's procedure \\
\hline Subtotal colectomy
\end{tabular} & $54(6 \%)$ & $34(28 \%)$ \\
\hline Miles' procedure & $14(1.6 \%)$ & $4(3.3 \%)$ \\
\hline Anterior resection of the \\
rectum
\end{tabular}


The current diagnostic and treatment methods are described in the algorithm for treatment of acute malignant colorectal obstruction (fig.2).

From 1009 patients operated for 24 years (1982-2005) with colorectal cancer with median age 67 years 378 patients (37.4\%) were over 70 years. 121 patients (12\%) underwent emergency surgery, 61 (51.4\%) being over 70 years of age. 99 patients were with malignant obstruction $(82 \%)$, with perforation and peritonitis -12 patients $(10 \%)$ and haemorrhage -10 patients $(8 \%)$. With left localization of the tumor were $62 \%$, right colon $-24 \%$, rectum - 17 patients $(14 \%)$ (fig.1).

In the planned surgery group of patients the tumor was localized in the left colon in $34.2 \%$, in the right $-28.1 \%$ and in the rectum $-37.7 \%$ (Pavlidis T.E. et al.) (tabl.1).

In the emergency operations group no macroscopic spread of the disease was observed in 50 patients $(57.8 \%)$, while in $51(42.2 \%)$ a progression of the disease was observed; $18.2 \%$ of the patients were with liver metastases, $14 \%$ with invasion to adjacent organ and $12(10 \%)$ - diffuse intraabdominal dissemination (tabl.2).

No macroscopic dissemination was observed in $58 \%$ of the emergency operations and in $72 \%$ of the elective operations

Emergency operation with resection and primary anastomosis was performed in 57 patients (47.3\%), Hartmann 34 patients (28\%), colostomy - 23 patients (19\%), palliative excisions $-4(3.3 \%)$, ileo-transversoanastomosis -3 patients $(2.4 \%)$ (tabl.3).

The rate of resectability for emergency operations was $75 \%$, while for the planned surgery was $95 \%$ (tabl.3.) (19).

The decompressive colostomy is performed only in oncologically inoperable patients, while the primary anastomisis is the method of choice (17).

In our study the operations on the right colon were right hemicolectomy (primary resection with anastomosis) -87 patients $(24.9 \%)$. The rate of primary resections with anastomosis for left colon cancer was $32.4 \%$, the primary discontinuity resections - 34.6\% (on 121 patients); decompressive enterostoma with delayed resection-5.1\%. The primary resections with anastomosis are about $58.8 \%$ and with the primary discontinuity $-35 \%$.

An important characteristic of this group of patients is the advanced stage of the cancer. 231 patients (66\%) were in $\mathrm{III}^{\text {rd }}$ and IV ${ }^{\text {th }}$ stage. The primary resections with anastomo-

Tabl. 4. Distribution of patients with colorectal cancer according to Dukes (Pavlidis T.E. et al.)

\begin{tabular}{||l|c|c||}
\hline Stage & Elective surgery & Emergency surgery \\
\hline A & $115(13 \%)$ & $1(1 \%)$ \\
\hline B & $367(41 \%)$ & $53(44 \%)$ \\
\hline C & $263(30 \%)$ & $32(26 \%)$ \\
\hline D & $143(16 \%)$ & $35(29 \%)$ \\
\hline Total & $\mathbf{8 8 8}$ & $\mathbf{1 2 1}$ \\
\hline
\end{tabular}

sis (radically operated) accounted $62.8 \%$ for second stage, third stage $-60.9 \%$, fouth stage $-50 \%$. There is no significant difference in the rate of the performed operations except for the more frequent discontinuity operations and decompressive ostomies in case of $\mathrm{IV}^{\text {th }}$ stage cancer.

Our study demonstrates that 202 patients $(57.7 \%)$ were in $\mathrm{III}^{\text {rd }}$ and $\mathrm{IV}^{\text {th }}$ stage of obstruction. The primary resections with anastomosis in $\mathrm{I}^{\text {st }}$ stage were $83.7 \%$ and decreased to $50 \%$ for $\mathrm{IV}^{\text {th }}$ stage cancer, where the number for primary discontinuity resections was the same.

The frequency of cell differentiation was as follows: $16.5 \%$ with poorly differentiated, $63 \%$ - moderately differentiated, $20.5 \%$ - with well differentiated. There was no significant difference between emergency and elective operations, as well as between patients over 70 years and under 70 years and the depth of invasion (19).

Cancer stage was more advanced in patients with emergency operation in comparison to those with planned surgery and over 70 years (acc. to Duke's stage - tabl.4). From oncological point of view the emergency operations established wider spread of the disease with higher number of metastatic and resected lymph nodes.

The letality in the emergency surgery group was 5.8\% (7 patients) or $8.2 \%$ for patients over 70 and $3.3 \%$ for patients under 70 , and the morbidity was $20 \%$ (19). The emergency operations for patients over 70 years were associated with higher morbidity of $42.6 \%$ and mortality $-27.8 \%$, as well as higher rate (19).

Predictors for postoperative lethality for patients with ileus-carcinoma are: emergency operation, loss of body weight more than $10 \%$, history of neurological disesase, age over 70 years, high APACHI II index, there is also individual risk-index (Kr. Ivanov).

The early diagnosis and staging before the acute presentation of the disease are crucial in the operative treatment, as well as the need for screening of high-risk patients.

The most important aim is to overcome the obstruction and restore the intestinal passage and if possible perform a resection of the tumor $(19,21,23,9)$.

In case of malignant left colon obstructions the decision for resection with primary anastomosis is difficult because of the dilated colon, which is filled with feces, the poor general condition and the high risk of anastomotic leakage. This led to the development of many methods - single, double and three stage surgery $(9,16,19,21)$.

The three-stage surgery was the most widely used method until the 70ties and was considered the only safe approach for malignant obstructions of the left colon.

The disadvantages of this approach are the frequent operations, all of them resulted in ostomy and in 25\% the ostomy was never closed, which have worsened the quality of life (9). The double stage operations were introduced later and led to more frequent resection of the tumor with closure of the distal colon and terminal ostomy, as well as primary operation (e.g. Hartmann's procedure). The closure of the ostomy was performed on second stage. The hospital stay was shorter in comparison to the three-stage operations, but 
the ostomy was never closed in $60 \%$ of the patients (9), because of advanced age and severe comorbidity.

Some patients may reject ostomy because of religious consideration $(9,21)$.

The double stage operation for malignant obstruction of the left colon is the most safe procedure. With this diagnosis were operated 56 patients. In 12 patients was performed laparotomy, and in the rest - primary colostomy (median age 76 years). Among 42 survivours the second operation was not performed in 6 patients (poor general condition or progression of the disease). In 34 resections the ostomy was closed in 28 patients, and in 6 patients was closed much later. The staging was as follows (Dukes): B - 3 patients, C $-19, \mathrm{D}-14$ patients (6).

In a retrospective study of 115 patients (Sjodahl R. et al.) with primary or multi-stage resection for malignant obstruction of the colon the complications were $15 \%$ for primary resection (Hartmann's operation - 27.8\%, single-stage resection $-73 \%$ ) and $25 \%$ for multi-stage operations. The increased morbidity is related to the ostomy; the morbidity after primary and staged resections is $10 \%$ vs $15 \%$, respectively. Better results are observed after Hartmann's procedure in comparison to triple stage and especially after single-stage operations (17).

The completion, forming and closure of the ostomy in single-stage operations was related with mortality rate of $7 \%$ and morbidity rate of $21-37 \%$ (17). The passage was not restored in $25 \%$ to $50 \%$ of the patients due to high operative risk or comorbidity, patient's poor cooperation, worsened quality of life.

The complications were the same in single-stage and multi-stage operation and the method had no influence over mortality, as well as the stage of the disease and APACHI II score (17).

There is a discussion which is the best operative methods for treatment of malignant colonic obstruction (17).

Two single-stage operations deserve more attention: subtotal colectomy and segment resection with intraoperative decompression (22).

The subtotal colectomy ( $32 \%$ in Minessota, USA) has decreased the complications from the anastomosis, because the ileo-colo and ileo-rectal anastomosis were performed when the lumen is normal and not on dilated colon.

Synchronous lesions were observed in $3 \%$ to $5 \%$ of cases with left colon cancer, but they could not be removed with subtotal colectomy. No further follow-up is required after removal of metachronous lesions. The subtotal colectomy is often related with fecal incontinence, which is not typical for the segment resection.

The primary resection of the colon with latero-terminal anastomosis with stapler and with the use of protective colostomy is the alternative method for selected patients. This type of enterostomy is described in 1961 by Santulli and Blanc. The enterostomy is closed by local incision. It is described in 10 patients (16) and it gives safety and proximal decompression and the benefits of the primary anastomosis (16).

Primary anastomosis was performed in 83 patients with malignant obstruction of the colon. With right colon cancer were 36 patients $(43.3 \%)$, left colon cancer $-47(56.7 \%)$. In
45 patients was performed intraoperative decompression and anastomosis. The late results are compared to $369 \mathrm{pa}-$ tients with colon cancer without obstruction (39\% right and $61 \%$ left colon cancer). The morbidity was $25.3 \%$ and the lethality - 6\%; anastomotic leakage was observed in $6 \%$. The five-year survival was poorer in patients with malignant obstruction in comparison to those without ileus. The malignant obstruction is associated with advanced age and advanced stage of the disease (3).

Tabl. 5. Localisation of the cancer causing malignant obstruction.

\begin{tabular}{||l|c|c||}
\hline \hline $\begin{array}{l}\text { Localisation of the } \\
\text { cancer }\end{array}$ & Group $\mathbf{1} \mathbf{n = 7 2}$ & Group II $\mathbf{n = 7 4}$ \\
\hline Transverse colon & - & 1 \\
\hline Lienal flexure & 1 & 24 \\
\hline Descendant colon & 4 & 7 \\
\hline Sigma & $\mathbf{6 7}$ & $\mathbf{4 2}$ \\
\hline
\end{tabular}

Group I-patients underwent Hartamnn's procedure.

Group II-patients underwent subtotal colectomy.

The advantages of the single-stage operations are avoiding of ostomy and need for only one operation. Most oftenly was performed a resection of the colon with intraoperative decompression of the pre-anastomotic part of the colon or subtotal colectomy $(9,13,21)$.

One randomized study demonstrates that both methods are equally safe, but the late results after subtotal colectomy are worse (9).

Two groups of patients with malignat obstruction are described in second and third stage of the disease, which underwent emergency surgery for a period of six years $(2000-$ 2006). 74 patients with subtotal colectomy were included in the first group, in whom the passage was restored immediately with ileo-sigmoanastomosis. The operative method depends on the choice and experience of the surgeon (2). The patients have been hospitalized due to colonic obstruction in second and third clinical stage, requiring emergency surgery.

The indications for subtotal colectomy are described more proximal localization of the tumors, higher risk for synchronous and metachronous tumors (5), younger patients and family history (9); this operation proves as oncologically safe.

According to different authors the postoperative complications after operation are observed in $8 \%$ to $28 \%$. The most frequent complications are anastomotic leakage (2-28\%), postoperative diarrhea (up to $31 \%$ ), wound infection, infection of the urinary system, ileus, respiratory insufficiency, etc $(2,9)$.

The lethality varies from $3 \%$ to $23 \%$ and in some selected gropus reaches $0 \%$. In comparison to the planned surgery the mortality was $2 \%-13 \%$, and after primary resection with restoration of the colon continuity on second stage (Hartmann's procedure) reaches $10-25 \%(2,9)$. 
The decompression takes time when it is not performed correctly and may lead to catastrophic feculent peritonitis. The question about simple pre-anastomotic decompression remains. May be the difference between the two options remains scarce, but both are technically difficult and the large operations can be compromised in hemodynamically unstable patients (9).

Tabl. 6. Anastomtic leakage in single stage operations:

\begin{tabular}{||l|c|c|c|c||}
\hline \hline Author & Year & $\begin{array}{c}\text { Group 1 } \\
\mathbf{( \% )}\end{array}$ & $\begin{array}{c}\text { Group 2 } \\
\mathbf{( \% )}\end{array}$ & $\begin{array}{c}\text { Group 3 } \\
\mathbf{( \% )}\end{array}$ \\
\hline SCOTIA & 1995 & - & 7 & 9 \\
\hline Nyam & 1996 & 0 & 3 & - \\
\hline $\begin{array}{l}\text { Van } \\
\text { Gekdere }\end{array}$ & 2002 & 1.2 & - & - \\
\hline \hline
\end{tabular}

Group 1 - segment resection, anastomosis, without bowel preparation

Group 2-segmental resection, anastomosis, intraoperative lavage

Group 3-subtotal colectomy, anastomosis

The subtotal colectomy is recommended in patients with perforation of ischaemic coecum or with synchronous lesions in the proximal colon (SCOTIA group). In all other cases is recommended a segment resection with decompression. The primary anastomosis without mechanical decompression is revised in 30 years.

The single stage operation of choice is wide resection of the colon with primary anastomosis - "safe operation for malignant obstruction of the colon" (9). It is possible in $70 \%$ of the patients (21).

From 23 patients with malignant obstruction of the left colon (39 to 83 years of age) in 14 patientsis performed a single stage operation with primary anastomosis (in 10 with intraoperative decompression, 4 with subtotal colectomy), in 4 - Hartmann's procedure, in 5-colostomy). The rate of the anastomotic leakage after primary resections with anastomosis was $7.1 \%$, and in multi-stage resections was $22.2 \%$ (7).

The primary resections with anastomosis after decompression were related with $10 \%$ ad $5 \%$ rate of anastomotic leakage $(9,19,21)$.

In all patients was performed a primary anastomosis after segment resection with intraoperative lavage - pro- and retrogradient, in compliance to the oncological standarts (68\% in Minessota). The overall morbidity was $11 \%$, the mortality $-12.5 \%$. $15 \%$ of the subtotal colectomy cases were with permanent ostomy, after segment resection $2 \%$, the rate of anastomotic leakage was $7 \%$ and the mortality was $11 \%$. The rate of anastomotic leakage and morbidity after subtotal colectomy was $9 \%$ and $13 \%$, respectively.

The mortality after colonic resection due to obstructive cancer was $4 \%$ to $10 \%$ and the anastomotic leakage reached 0-4\% (SCOTIA group).

The study of the SCOTIA group focused on the evaluation of the disadvantages of each operation.
In comparison to males the female gender bared higher risk of malignant colonic obstruction with the increase of age, higher risk of incomplete cure and shorter survival compared to those without obstruction. The five-year survival in patients with obstructive cancer was $35.8 \%$ vs. $55.5 \%$ in those without obstruction. The chance in the first group is worst due to the more advanced stage of the disease (17). The obstructive adenocarcinoma is $22-33 \%$ Duke's stage C, $14-29 \%$ stage D. $62-72 \%$ of the patients undergo radical surgery after surgeon's decision (17).

The choice of emergency surgical procedure for malignant obstruction of the left colon remains controversial subject (22). The emergency surgery bears a significant risk of lethality, morbidity and high number of colostomies - temporary and definitive.

A COCHRANE systematic review compares the multi-stage operations vs. primary resection and significant differencies in lethality or mortality were observed. The primary resections for acute malignant obstruction of the left colon are standart treatment of choice for many surgeons, but the type of operation is debated (22).

In 9 randomized meta-analyses 7 of them don't prove that mechanical preparation of the bowel is related to lower rate of anastomotic leakage after planned surgery (22). One randomized study compares the lavage with manual decompression and no significant differencies in lethality and morbidity was observed, but it proved to be easier than lavage. Another study shows that manual decompression is not a safe method (22).

In England the Association of Coloproctology performed a study and established four predictors for the treatment result of malignant obstruction of colon and rectum - age, ASA, emergency and Duke's stage (22).

The analysis shows that the safety of segment resection of primary anastomosis without colonic preparation or decompression for overcoming of obstruction and defecation. The single stage resection is better preferred than segment resection with lavage or subtotal colecomty, although no prospective randomized trials support this (17).

From 1986 to 2003214 patients have been operated with acute colonic obstruction with single stage resection and anastomosis. From 80 patients with obstruction 71 of them were with right colon cancer. The operative mortality was $10 \%$ (8 of 80 patients), $2.5 \%$ with anastomotic leakage. From 134 patients with obastruction of the left colon 127 were with cancer. The operative mortality was $1.5 \%$ ( 2 of 134 patients) (25).

The lowest mortality rate after emergency surgery for colonic ileus-cancer is about 3\%, even when experienced surgeons operate. Most often it is 10 to $25 \%(14,9)$.

The safest procedure must be chosen for patients with very high risk (22). The consensus questionnaire in 2002 in USA for colorectal surgeons shows that $67 \%$ would perform Hartmann's procedure and $26 \%$ consider that it is preferable to perform only colostomy in patients with high risk.

A dilemma remains in the case of non-resectable tumors with peritoneal carcinomatosis and colonic obstruction. Ascites was established intraoperatively. The 
carcinomatosis was never fully evaluated because of adhesions or small incision (10).

The median period between the primary and palliative treatment was 14 months (form 3.5 to 61 months). 9 patients underwent primary resection, 6 - colostomy (5 of them with transversorectostomy and 1 with transversosigmostomy), 11 patients - colonic bypass (3with double, 2 - with triple, 1 - with colonic resection without removal of the tumor), 3 bypass with colostomy (21 patients totally). No anastomotic leakage, mortality and morbidty were observed. Postoperative chemotherapy was applied to 7 patients (10).

The obstructive recurrence was observed 61 days medially with asymptomatic period (14 patients) with less than $100 \mathrm{ml}$ of ascites, but in a group of 7 patients the ascites was over $100 \mathrm{ml}$, the recurrence was observed after 9 days, as well as with postoperative chemotherapy. The levels of tumor spread can be proven even if few levels of obstruction are observed. The peritoneal carcinomatosis may cause problems in the passage due to secondary paralysis and invasion to the mesenterium, which cannot be solved by bypass surgery. This paramether can be significant for the asymptomatic survival (10).

The peritoneumectomy and the perioperative chemotherapy may be used as palliative care for colonic obstruction in caseof recurrent colorectal cancer (10).

The lethality after palliative surgery is $21 \%$. It may be applied with safety, especially in the absence of ascites, because the postoperative results are unexpected - no mortality and morbidity was observed (10).

Meta-analyses have compared the stenting vs. surgery in case of obstructive colorectal cancer. The stenting is related with significantly lower morbidity and mortality, lesser number of complications, shorter hospital stay even in patients with stenting as the only therapeutic option, faster recovery, cheaper than surgery, although the stent itself is ex- pensive. The placement of the stent is not a contraindication for preoperative chemotherapy if required (21).

In case of obstructive cancer of the left colon the surgery is indicated when there is a suspicion for infarction of the colon or perforation, peritonitis, acidosis, sepsis, non-adequately placed stent $(9,21)$.

The self-expandable stent are used:

1. For palliative procedure in incurable cases:

In a study including 168 patients who underwent stenting as palliative care, quick recovery was observed in 96.9\%; 41 (24.4\%) suffered complications: perforation $9 \%$, occlusion $9 \%$, migration $5 \%$, erosion or ulceration $2 \%$ (E. Bonin et al.). Stenting and surgery was performed on 44 patients with obstructive colonic cancer and extracolonic cancer in incurable patients. Successfully stented were 30 patients, in 14 patients was performed ostomy; $80 \%$ of the patients in both groups were with better scoring after 28 months.

2. Bridge to surgery for colonic decompression and consequtive radical resection with primary anastomosis:

A randomized study of stenting as bridge to surgery have established that in 48 patients with left colon cancer 24 were stented with consequent laparoscopic resection and other 24 underwent emergency open surgery. The laparoscopic surgery decreased blood loss, the rate of anastomotic leakage and wound infections was lower. The single-stage surgery with primary anastomosis was was $16 / 9$. None of the patients from the laparoscopic group had permanent ostomy in comparison to 6 patients from the emergency open surgery group.

In 8000 patients who underwent emergency surgery the mortality was $19.3 \%$ compared to $5.6 \%$ after planned surgery. The patients with acute malignant obstruction of the colon and rectum underwent emergency surgery $-41 \%$ had primary anastomosis, compared to $87 \%$ of those who

Tabl.7. Indications for treatment, advantages and problems in malignant left-sided colonic obstruction. (Trompetas V, 2008, (22)

\begin{tabular}{|c|c|c|c|}
\hline & Indication & Advantages & Problems \\
\hline Stenting & Palliation Bridge to surgery & Less colostomies Less mortality & $\begin{array}{l}\text { Less centers have the possibility } \\
\text { for stenting. Not always } \\
\text { successful. The long-term results } \\
\text { are unknown }\end{array}$ \\
\hline $\begin{array}{l}\text { Single-stage resections with } \\
\text { anastomosis }\end{array}$ & Low risk patients & No colostomy & Anastomotic leakage \\
\hline Intraoperative lavage of the colon & $\begin{array}{l}\text { In combination with single-stage } \\
\text { resection with anastomosis }\end{array}$ & Need for colonic preaparation & $\begin{array}{l}\text { Time-consuming No prove for its } \\
\text { necessity }\end{array}$ \\
\hline Subtotal colectomy & $\begin{array}{l}\text { High lesions of the colon due to } \\
\text { obstruction or synchronous tumors }\end{array}$ & Safe as segment resection & Large surgery Diarrhea \\
\hline Hartmann's operation & $\begin{array}{l}\text { High-risk patients Inexperienced } \\
\text { surgeon }\end{array}$ & No risk for anastomotic leakage & $\begin{array}{l}\text { Need for next large operation for } \\
\text { restoration of the passage. In } \\
\text { many patients the colostomy is } \\
\text { never closed. }\end{array}$ \\
\hline Only colostomy & $\begin{array}{l}\text { Palliation for very high-risk } \\
\text { patients }\end{array}$ & $\begin{array}{l}\text { The only option if stenting is } \\
\text { impossible }\end{array}$ & Care of the colostomy \\
\hline
\end{tabular}


had primary stenting and after that underwent planned surgery (Martinez-Santis, 24).

The stenting and non-operative decompression in case of obstructive left-colon cancer was probably the most impressive advance in the modern coloproctology $(9,21)$. The clinical and technical success rate was up to $90 \%$.

\section{Cecostomy and laser}

Cecostomy is accompanied with many complications (often obstruction). It is applied as single operation or as definitive treatment after surgery or when the condition of the patient doesn't allow further operations. The morbidity and mortality are $15 \%$ and $24 \%$, respectively (17).

\section{NdYAG laser}

It is widely applied for palliative treatment as represents an effective option for overcoming of the obstruction and decreasing the bleeding after radio- and chemotherapy; it is an alternative to the permanent colostomy (17).

The choice between primary resection and anastomosis or multi-stage resection as radical surgical treatment for malignant obstruction of the left colon is debatable. Further comparative studies are required and further clarification of the rates of morbidity and mortality, although 2043 citation on this subject can be found (8) (tab.7).

"Whatever you do, some people will be unhappy. If you do a colostomy there will be always someone to ask you why not primary anastomosis? If you do a primary anastomosis there will be always someone to say why not colostomy? (M. Schein et al) - the decision is made by the surgeon depending on his knowledge and experience.

\section{REFFERENCES}

1. Ivanov $\mathrm{Kr}$ - New directions and surgical treatment of the colorectal cancer, Dissertation, Sofia 2008

2. Petrov S, M. Tadjer, Yu. Vanev, Sh. Tadjer - The role of the subtotal colectomy in the surgical treatment of advanced colonc ileus of neoplastic origine, $X^{\text {th }}$ Anniversary National Conference of Coloproctology, Varna, 2007

3. Baccari P., D. Bisagni P., Operative And Long Term Results After One-Stage Surgery For Obstructing Colonic Cancer - Hepatogastroenterology, vol. 53, 71, 698-701

4. Bonin Eduardo, T. Baron et al., Update Of The Indications And Use Of Colonic Stents, Current Gastroenterol. Rep. (2010)12, 374-382.

5. Burada A., Peki Sen Nerdesin et al., Colonic Stenting No More Effective Then Emergency Surgery In Patients With Malignant Bowel Obstruction - Cancer Oncology, 7, 29, 2011.

6. Cugneuc P.H., Berger A., Two-Stage Surgery Of Neoplastic Left Colonic Obstruction Remains The Safest Procedure - J. Chir., Paris, Dec. 1997, 134, 275-278

7. De Aguilar-Nascimento J.E., C. Caporossi et al., Comparison Between Resection And Primary Anastomosis And Staged Resection In Obstructing
Adenocarcinoma Of The Left Colon - PubMed, Scielo.org

8. De Salvo, C. Gava et al., Curative Surgery For Obstruction From Primary Left Colorectal Carcinoma: Primary Or Staged Resection? - Cochrane $S$. Rev., 2009

9. Douglas Stupart, Most Cases Of Large Bowel Obstruction Are Due To Colonic Adenocarcinoma CME, July, 2007, vol. 25, 7, 324-330

10. Hisato Higashi, H. Shido et al., Factors Affecting Successful Palliative Surgery For Malignant Bowel Obstruction Due To Peritoneal Dissemination From Colorectal Cancer - Jap. Journal of Clin. Oncology, 2003, 33, 357-362

11. Johnatan S., I. Igen et al., Cancer Emergencies: The Acute Abdomen - Emergency Medicine, Clin. N. Am., 27 (2009), 381-399.

12. J. E. Van Hooft et al., Colonic Stenting Versus Emergency Surgery For Acute Left-Sided Malignant Colonic Obstruction: A Multicentre Randomized Trial - Lancet Oncology, 2011, 12, 344-352.

13. Khot UP, Lang AW, Murali K, Parker MC. Systematic review of the efficacy and safety of colorectal stents. Br J Surg. 2002;89:1096-1102.

14. Law W.L., H.K. Choi, K.W. Chu, Comparisson Of Stenting With Emergency Surgery As Palliative Treatment For Obstructing Primary Left-Sided Colorectal Cancer - Br. J. Surg., 2003, Nov., 90 (11), 1419-1433.

15. S.M. Steinberg, J.S. Barkin, R.S. Kaplan, D.M. Stablein Prognostic indicators of colon tumors, The Gastrointestinal Tumor Study Group experience Cancer, 57 (1986), pp. 1866-1870

16. Meijer WS, Vermeulen J, Gosselink MP. Primary resection and side-to-end anastomosis next to an end-colostomy in the management of acute malignant obstruction of the left bowel: an alternative in selected patients. Tech Coloproctol. 2009 Jun; 13(2):123-6. Epub 2009 May 29.

17. Nicholl Michael, et al., Current Management Of Malignant Large Bowel Obstruction - Contemporary Surgery Review Article, Dept. Of Surgery, Med. Col. Of Wisconsin.

18. Oljnic I., Bodnarova M. et al., Subtotal Colectomy In The Treatment Of Acute Malignant Left-Sided Large Bowel Obstruction - Brasil Lek. Listy, 2009, 110 (7), 412 -5

19. Pavlidis T.E., G. Marakis, K. Balles et al., Does Emergency Surgery Affect Resectability Of Colorectal Cancer? - Acta. Chir. Belg., 2008, 108, 219-225.

20. Slim K., J. Panis, Alves A. et al. Predicting Postoperative Mortality In Patients Undergoing Colorectal Surgery - World J. Surg., 2006, 30, 100-106.

21. Targarona E.M. C. Balogu, Stenting Of Obstructing Colonic Cancer: A Real Advance Or An Irrelevance To The Laparoscopic Surgeon? - Surg. Endosc., 2005, 19 (7), 45-46

22. Trompetas Vasileios et al., Emergency Management Of Malignant Acute Left-Sided Colonic Obstruction - Ann. R. Col. Surg. Engl., 2008, 90, 181-186. 
23. A.M. Cohen What is the best treatment for stage IV colorectal cancer? Ann Surg Oncol, 12 (2005), pp. $581-582$

24. Williams D., R. Zaw et al., Colorectal Stenting In Malignant Large Bowel Obstruction: The Learning
Curve - Intern. Journal Of Surgical Oncology, vol. 2011, Article 18.

25. R. Lobianka, B. Nordinger, et al., Primary Colon Cancer - ESMO, Clinical Practice Guidelines For Diagnosis, Adjuvant Treatment And Follow Up, Ann. Of Oncology (Suppl.), 70-77, 2010. 